\title{
EVOLUÇÃO TERAPÊUTICA DA HANSENÍASE DA ERA CHAULMÚRGICA ATÉ O TRATAMENTO NACIONAL NA COLÔNIA DO PRATA, NORTE DO BRASIL
}

Natália Crispim da Costa $^{1}$, Giulia Oliveira de Macedo ${ }^{1}$, Alyne Costa de Miranda ${ }^{1}$, Francisca Amanda dos Santos Oliveira ${ }^{1}$, Carla de Castro Sant'Anna ${ }^{1}$, Marcella Kelly Costa de Almeida ${ }^{1}$, Bruno Leonardo Costa de Almeida ${ }^{1}$, Kemper Nunes dos Santos ${ }^{1}$

${ }^{1}$ Universidade da Amazônia E-mail para correspondência: costanatalia95@gmail.com Submetido em: 05/03/2020 e aprovado em: 23/06/2020

\section{RESUMO}

Introdução: A hanseníase é uma doença infecciosa causada pelo Mycobacterium leprae, enfermidade crônica, de acometimento dermatoneurológico, evolução lenta, na ausência de tratamento pode ser incapacitante e deformante. No início das epidemias, e sem tratamento comprovado, foram criados leprosários como medida profilática, que no Estado do Pará, Lazarópolis do Prata era referência. Objetivos: O objetivo da pesquisa foi comparar a terapia sequencial aplicada no antigo Lazarópolis do Prata, desde a utilização de derivados chaulmúrgicos à terapêutica atual, em relação ao progresso do tratamento nacional. Métodos: O estudo analítico retrospectivo utilizou dados quantitativos do leprosário de 1923 a 2017, correspondente ao período de admissão de pacientes. Resultados e discussão: Nos períodos avaliados, o gênero masculino teve maior prevalência de admissão (65,7\%). Entre 1935 a 2015, houve crescimento médio de 5 casos a cada 5 anos, cujas formas mais prevalentes apresentaram picos significantes de 1971 a 1975, representado pelo tipo virchowiana e 2011 a 2015 pelo aumento dos casos do tipo tuberculoide. Conclusões: A hanseníase ainda persiste como doença negligenciada e problema de saúde pública, porém, houve uma considerável mudança no perfil epidemiológico através das estratégias de medidas profiláticas e modulações no esquema terapêutico, como observado na Colônia do Prata.

Palavras-chave: Hanseníase, Terapia combinada, Amazônia, Mycobacterium leprae.

\begin{abstract}
Introduction: Leprosy is an infectious disease caused by Mycobacterium leprae, chronic illness, of dermatoneurological involvement, slow evolution, in the absence of treatment can be disabling and deforming. At the beginning of the epidemics, and without proven treatment, leprosaria were created as a prophylactic measure, which in the State of Pará, Lazarópolis do
\end{abstract}


Prata was a reference. Aims: The aim of the research was to compare the sequential therapy applied in the former Lazarópolis do Prata, from the use of chaulmurgic derivatives to current therapy, in relation to the progress of national treatment. Methods: The retrospective analytical study used quantitative leprosy data from 1923 to 2017, corresponding to the period of admission of patients. Results and discussion: In the evaluated periods, the male gender had a higher prevalence of admission (65.7\%). Between 1935 and 2015, there was an average growth of 5 cases every 5 years, the most prevalent forms showing significant peaks from 1971 to 1975 , represented by virchowian and 2011 to 2015 by the increase in cases of tuberculoid. Conclusions: Leprosy persists as a neglected disease and public health problem, however, there has been a considerable change in the epidemiological profile through the strategies of prophylactic measures and modulations in the therapeutic scheme, as observed in the Prata Colony.

Keywords: Leprosy, Polychemotherapy, Amazônia, Mycobacterium leprae.

\section{INTRODUÇÃO}

A hanseníase é uma doença infectocontagiosa, causada pelo Mycobacterium leprae, também conhecido como bacilo de Hansen, possui caráter crônico, de evolução lenta, curável e dermatoneurológica devido à infecção de células cutâneas e nervosas periféricas, manifestando lesões dermatológicas com alterações na sensibilidade e acometimento nervoso, podendo evoluir para incapacidades físicas e lesões deformantes ${ }^{(1,2,3)}$.

No início das epidemias, quando não havia tratamento comprovado, foram criados leprosários - espaços onde os doentes eram encaminhados como medida profilática à população sadia - que no Estado do Pará; norte do Brasil, tinha como referência o Lazarópolis do Prata, localizado no município de Igarapé-Açu, região amazônica, onde diversas plantas e susbstâncias foram aplicadas como possível tratamento curativo da hanseníase, como o batatão, enxofre, assacu e o óleo da semente da chaulmoogra ${ }^{(2,4)}$.

A partir do sec. XX, a chaulmoogra, utilizada na sociedade hindu para doenças de pele, especialmente a hanseníase, foi introduzida como tratamento a nível nacional em diversas formas de apresentação, tais como: pomada, pílulas e injeções do óleo no tecido subcutâneo $^{(3,4,5)}$. No Brasil, a planta foi importada e cultivada pelo Instituto Oswaldo Cruz no Rio de Janeiro, e o tratamento realizado através de associações do óleo da chaulmoogra a outras substâncias, sendo distribuído para os leprosários do Pará. O uso dos óleos chaulmúrgicos, teve grande importância no arsenal terapêutico da hanseníase durante o período de isolamento 
compulsório, sendo a droga inicial utilizada, promovendo melhora, mas sem comprovação de $\operatorname{cura}^{(4,5)}$.

A associação de efeitos colaterais, desconforto na administração, discordância sobre a efetividade da cura e o surgimento da sulfona (Promin ${ }^{\circledR}$ ) em 1941, fez com que o uso dos chaulmúgicos entrassem em declínio, assim como a profilaxia por isolamento compulsório ${ }^{(3,4,5)}$. As sulfonamidas sugiram no início da década de 1940, onde eram utilizadas no controle de infecções, sendo indicada como tratamento hansênico. A diaminodifenilsulfona ou dapsona (DDS), um antimicobacteriano bacteriostático, foi utilizado em monoterapia por anos, no entanto, a partir de 1960 foram constatadas sulforesistência pelo bacilo e recidivas da doença, sendo necessária sua associação a rifampicina em 1978, cuja ação representou maior eficácia e prevenção a resistência bacteriana anteriormente observada, principalmente em pacientes multibacilares ${ }^{(6,7)}$. Posteriormente, em 1981, a Organização Mundial de Saúde (OMS) adotou como único tratamento para Hanseníase a poliquimioterapia (PQT), composta por rifampicina, bactericida; dapsona e clofazimina, bacteriostáticas com fraca ação bactericida ${ }^{(7,8)}$. Porém, devido a um temor sobre a eficácia da PQT, o esquema só foi adotado pelo Brasil no início da década de 1990, devido ao aumento no número de casos, se tornando o único esquema de tratamento substituindo gradativamente os outros métodos farmacológicos empregados anteriormente como tratamento da hanseníase ${ }^{(5,7)}$. Esse tratamento inviabiliza a transmissão do bacilo em 72h após a administração da medicação, impossibilitando a evolução da doença, prevenindo deformidades por ela causadas e efetivando a cura ${ }^{(9)}$.

A evolução do tratamento e a regressão nos casos tem aproximado o Brasil da proposta adotada pela OMS, que é de um caso para cada 10.000 habitantes, mas por se tratar de uma doença negligenciada e sua endemia também estar relacionada com questões socioeconômicas, diagnóstico tardio e abandono terapêutico, o decréscimo na taxa de novos casos se mostra lento diante do desenvolvimento nacional ${ }^{(9,10)}$.

O Pará está no grupo de regiões onde se concentram a maioria dos casos de hanseníase ${ }^{(10)}$. Em 2016 o Estado estava na quinta posição na prevalência de casos nacionais, e segunda posição na região Norte do país, região que mais contribui com o surgimento de novos $\operatorname{casos}^{(11)}$.

Como objetivo deste estudo propomos avaliar a associação terapêutica administrada no Leprosário do Prata, localizado na Colônia de Santo Antônio do Prata, no município de IgarapéAçu, Norte do Brasil, e a evolução do tratamento aplicado a nível nacional, como impacto nos números de casos da colônia. 


\section{MÉTODOS}

Foi realizado um estudo investigativo e exploratório de caráter analítico retrospectivo dos esquemas terapêuticos aplicados no Leprosário do Prata a partir da utilização de derivados chaulmúrgicos até a PQT atual, comparados a evolução terapêutica nacional, no qual foram utilizados dados quantitativos e qualitativos do leprosário, no período de 1923 a 2017, que corresponde ao período histórico de atividade do leprosário quanto aos registros de entrada e saída dos pacientes internados ao longo do tempo.

A pesquisa de campo foi realizada na Colônia de Santo Antônio do Prata, interior do município de Igarapé-Açu, no Estado do Pará, localizado na região amazônica, norte do Brasil (figura 1). A colônia está localizada no quilômetro 18 do município, com população estimada em 3.000 habitantes, segundo o Instituto Brasileiro de Geografia e Estatística (IBGE) ${ }^{(12)}$.

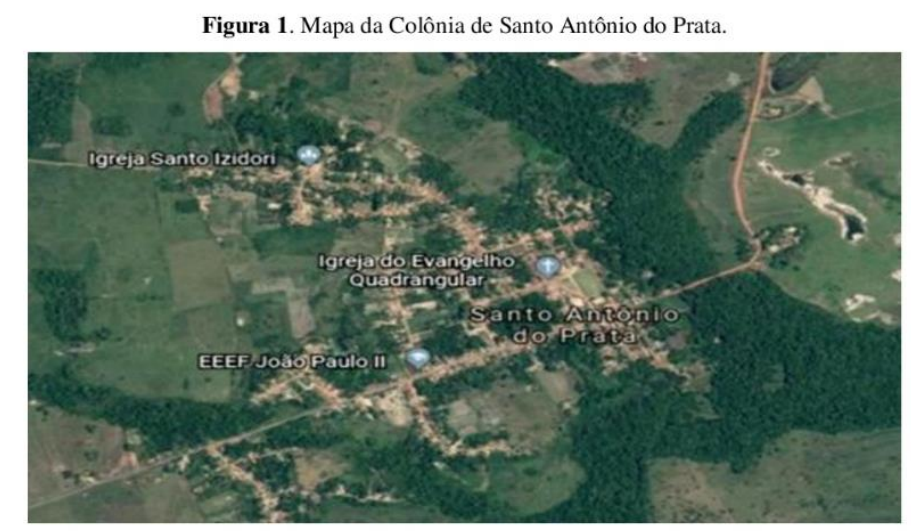

Fonte: Google Earth.

Foram investigados dados descritos em cadernos de registros contendo informações quanto ao tipo da doença (tuberculoide, dimorfa, indeterminada e virchowiana), local de origem e número de pacientes egressos hansenianos ativos e curados que constavam nos registros da colônia.

Os dados obtidos através dos arquivos históricos e registros do leprosário foram depositados em planilhas de Excel (Microsoft Office® versão 2007), os quais foram analisados e utilizados para gerar os resultados estatísticos representados em gráficos para observação das diferenças entre as variáveis analisadas, sendo considerado significância de $95 \%(p<0,005)$.

\section{RESULTADOS E DISCUSSÃO}

Os resultados da pesquisa demonstraram que entre o período de 1923 a 2017, sendo o primeiro ano marcado pela medida de isolamento compulsório e o último, como dado mais atual que consta nos registros manuais do antigo Lazarópolis do Prata, foi registrado um total 
de 1.486 pacientes hansênicos admitidos na Colônia do Prata, que até a década de 1940 foi utilizada como uma colônia de isolamento compulsório e posteriormente passou a ser um importante centro de tratamento e cuidados aos pacientes hansênicos já ali existentes e das localidades próximas do município de Igarapé-Açu/PA. Conforme observado na tabela 1, 976 $(65,7 \%)$ dos casos registrados foram de pacientes do sexo masculino. Este resultado pode estar relacionado ao menor cuidado dispensado à saúde por parte dos homens, caracterizando um grupo que pouco frequenta as unidades de saúde, como sugere o Ministério da Saúde, em seu boletim epidemiológico emitido em $2018^{(11)}$.

A terapia ao passar dos anos sofreu intensa mudança, devido ausência de tratamentos eficazes, por muito tempo. Após o investimento das pesquisas, o tratamento que anteriormente era exclusivo de caráter natural com a chaulmoogra (Taraktogenoskurzii), evoluiu à sulfona no início da década de 40, advinda com a potencialização da indústria de medicamentos após a segunda guerra mundial, e posteriormente para a PQT em $1980^{(4,13)}$.

\begin{tabular}{ccc}
\multicolumn{3}{c}{ Tabela 1. Casos de admissão de acordo com o sexo. } \\
\hline & Freq. & $\%$ \\
Feminino & 510 & 34.32 \\
Masculino & 976 & 65.7 \\
Total & 1486 & 100 \\
\hline
\end{tabular}

Atualmente a colônia de Santo Antônio do Prata é povoada por famílias constituídas a partir de pacientes hansenianos e funcionários do antigo leprosário Lazarópolis do Prata, oficialmente instalado como local de isolamento compulsório no ano de 1924. A partir dos dados coletados durante a realização da pesquisa em campo, observamos que o número de casos apresentou um acréscimo médio de 5 casos a cada cinco anos de admissão, entre os anos de 1935 e 2015 (gráfico 1). 


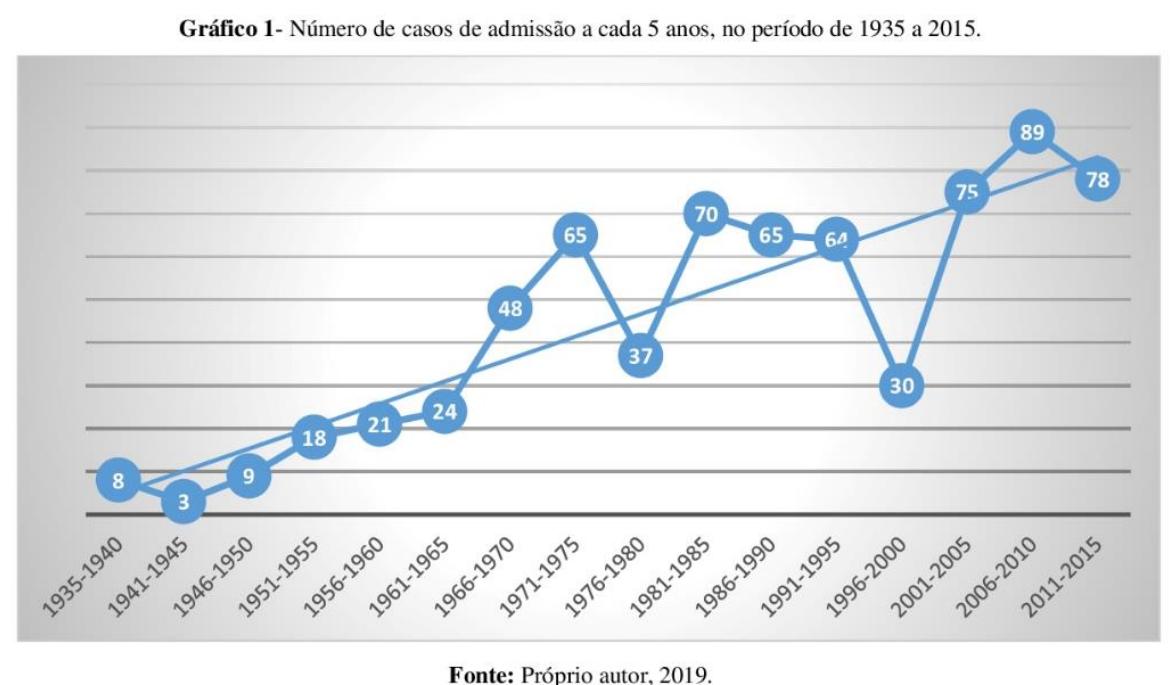

Entre os anos de 1935 a 1960 houve um baixo índice de admissão de novos casos no leprosário do Prata, fato que pode se justificar pela subnotificação da doença neste período, em vista das dificuldades do diagnóstico clínico precoce, isto é, da verificação da doença em sua fase inicial ${ }^{(14)}$. O número de admissões que ocorreram entre os anos de 1960 a 1970, aumentaram em 65 casos, sendo que neste período o país adotava o tratamento em monoterapia. Estudos evidenciam que nas décadas de 60 a 70 houveram registros de resistência medicamentosa à monoterapia sulfônica, como resultado do uso irregular deste esquema terapêutico ${ }^{(15)}$.

Nos anos de 1975 a 1980 foi observado uma diminuição do número de casos de admissão na Colônia do Prata, que pode ter ocorrido devido a mudança no esquema terapêutico, onde houve a inclusão de Rifampicina para os doentes multibacilares e a monoterapia sulfônica para os paucibacilares em longos períodos de tratamento (no mínimo 5 anos para os multibacilares e 2 anos para os paucibacilares) ${ }^{(16)}$. Entretanto, observamos um aumento nos casos registrados no leprosário após a implantação da PQT na década de 80, que adotou a associação da Rifampicina ao tratamento dos pacientes paucibacilares, e da Clofazimina ao tratamento dos doentes multibacilares, os quais também passaram a receber a Rifampicina em doses intermitentes durante todo o tratamento ${ }^{(11)}$. Visto que diversos efeitos colaterais são atribuídos aos medicamentos utilizados na PQT, este fator somado a falta de entendimento sobre o tratamento e o estigma, pode ter contribuído efetivamente para o afastamento do paciente até então assistido pelo programa de controle ${ }^{(17)}$.

No período que compreendeu os anos de 2000 a 2005, os casos novamente diminuíram, fato que pode estar associado a implantação de políticas públicas de saúde, que segundo Costa 
et al., (2015), após o Brasil adotar o modelo de descentralização da gestão da assistência à saúde da população, alocando recursos financeiros específicos para o custeio das ações básicas em saúde e com equipes nas unidades de atendimento em hanseníase que passaram por capacitação no município, na rede básica de saúde, tendo experiência em situações de diagnóstico, tratamento, surtos reacionais e prevenção de incapacidades, contribuiu para a melhora e diminuição de $\operatorname{casos}^{(18)}$.

Entre os diferentes tipos clínicos diagnosticados da doença, podemos observar que no período de 1935 a 2015, as formas mais prevalentes registradas - virchowiana e tuberculoide apresentam picos entre 1965 a 1975 e 2011 a 2015, respectivamente (gráfico 2).

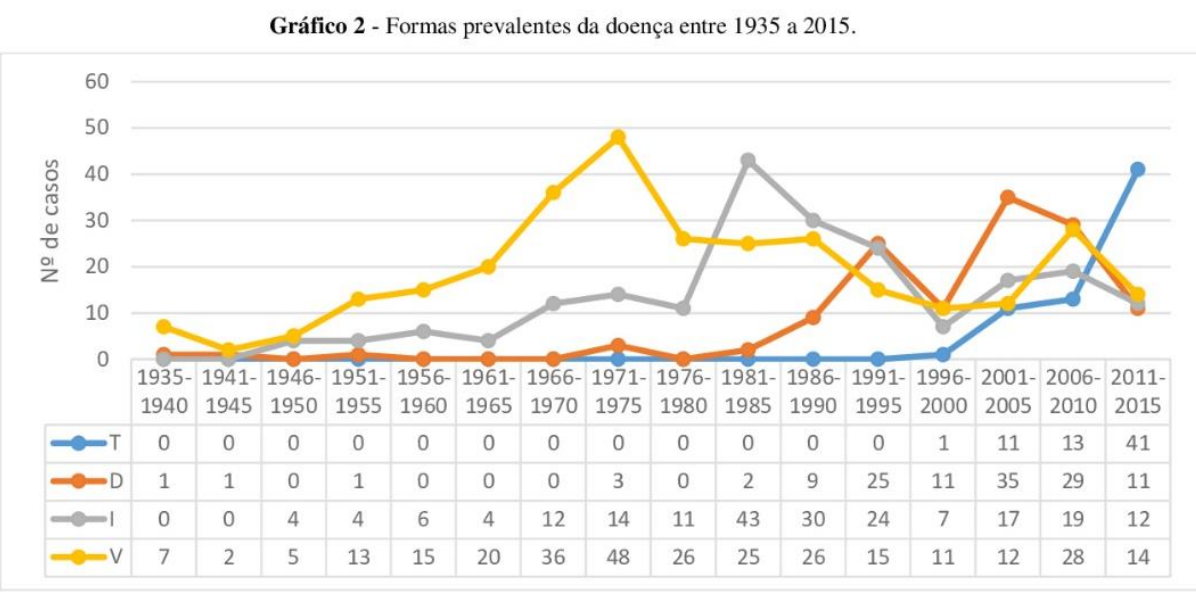

Tipos de Hanseníase descritos no Gráfico: T - Tuberculoide; D - Dimorfa; I - Indeterminada; V - Virchowiana. Fonte: Próprio autor, 2019.

Foi possível observar durante o estudo um pico da hanseníase virchowiana entre os anos de 1965 a 1975, que é a forma onde os indivíduos apresentam imunidade celular menos eficaz contra o Mycobacterium leprae tendo alto índice de contagio nos casos não $\operatorname{tratados}^{(11)}$. $\mathrm{O}$ aumento no número de casos diagnosticados foi impulsionado pela mudança do termo lepra para hanseníase, que na década de 1970 teve o Brasil como pioneiro nessa substituição, fazendo com que a doença fosse melhor reconhecida, no intuito de promover a conscientização da população, a fim de afastar os preconceitos e divulgar informações da doença gerando uma nova concepção sobre a enfermidade ${ }^{(15)}$.

No ano de 1996 foi registrado o primeiro caso de hanseníase tuberculoide na Colônia do Prata, que a partir de então apresentou um progresso gradativo no número de casos ao longo dos anos seguintes. Este dado poder ser explicado por ser um tipo da doença onde os indivíduos possuem alta resistência ao bacilo ${ }^{(19)}$, deixando de ser evidenciada nos anos anteriores.

Podemos evidenciar que dos casos de hanseníase registrados na colônia do Prata, no período de 1935 a 1977, as principais localidades de origem dos pacientes admitidos foram das 
regiões norte, nordeste, sudeste e sudoeste do Estado do Pará, recebendo uma média de mais de 15 casos por região (figura 2).

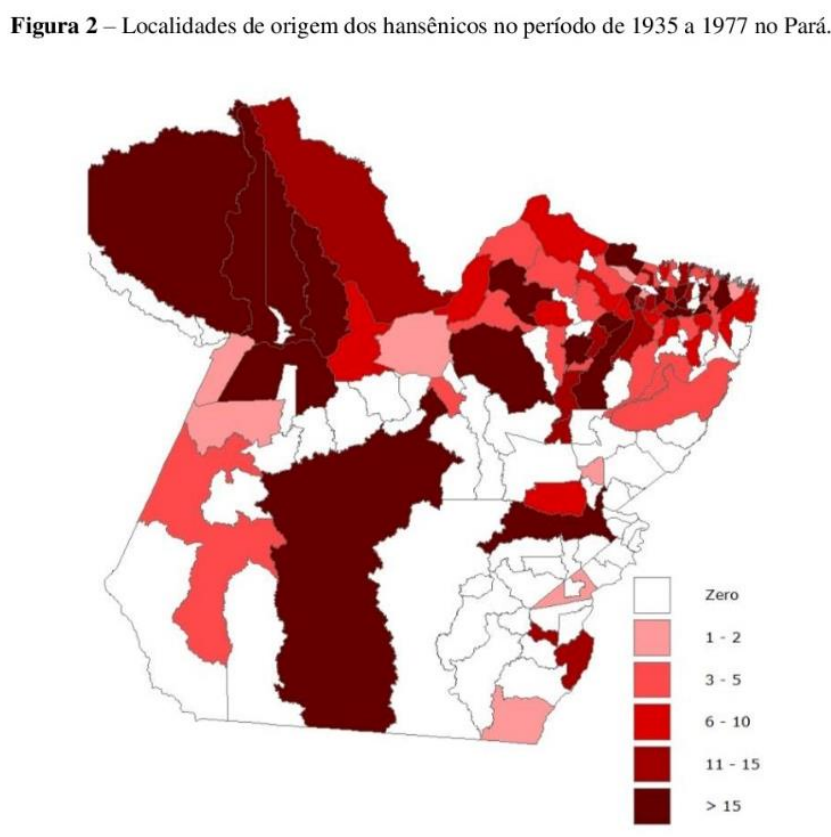

Fonte: Próprio autor, 2019

Após a fundação do Leprosário do Prata no início da década de 20, como uma das primeiras colônias agrícolas de leprosos fundada no Brasil ${ }^{(4)}$, muitos portadores de hanseníase foram acolhidos, tanto do Estado do Pará quanto de outros estados. Os pacientes advindos de outros Estados representam um número insignificante de admissão, mas dentre os mesmos anos, os estados do Maranhão, Amapá e Roraima, destacam-se em números de admissão. Os dados deste resultado só constam até o ano de 1977, devido os registros utilizados para esta pesquisa, disponibilizados pela atual Colônia do Prata, constando apenas as localidades de egresso até esse período.

\section{CONCLUSÕES}

A hanseníase ainda persiste como uma doença negligenciada e um problema de saúde pública, apesar da considerável mudança no perfil epidemiológico através das estratégias de medidas profiláticas e modulações no esquema terapêutico, caracterizando a importância e a contribuição que esses centros de "acolhimento" tiveram neste contexto, validando o valor da preservação histórica do perfil epidemiológico da hoje intitulada Colônia do Prata, que apesar da perda de importantes documentos ao longo do tempo, tem muito a contribuir com a pesquisa cientifica na área, mas requer por uma atenção e um cuidado maior daqueles que ainda podem 
contribuir para que este importante acervo cultural na história da saúde não seja perdido definitivamente em poucos anos.

\section{REFERÊNCIAS BIBLIOGRÁFICAS}

1. Cunha DV, Rodrigues EB, Lameira HA, Cruz MTS, Rodrigues SM, Santos FS. Perfil epidemiológico da hanseníase no município de Castanhal - Pará no período de 2014 a 2017. Rev. Eletrônica Acervo Saúde. 2019; 11(15): e858.

2. Lopes RCS. Lepra, políticas sanitárias e controle social: isolamento e cotidiano na Lazarópolis do Prata, Pará. Vestígios - Rev. Latino Americana de Arqueologia Histórica. 2018; 12(1): 59-84.

3. Oliveira CM, Machado AMRC, Alves RCSP, Mar ZS, Fecury AA, Dias CAGM, Oliveira E,

Dendasck C. A evolução da assistência ao paciente com hanseníase: dos leprosários à poliquimioterapia. Rev. Científica Multidisciplinar Núcleo do Conhecimento. 2016; 6(8): 6880.

4. Muniz ES, Linhares PO. Sobre óleos, sabonetes e asilos. Veredas - Rev. Interdisciplinar de humanidade. 2019; 2(3): 77-96.

5. Frutuoso RAM, Ferreira GRD, Frutuoso SB. Da maldição ao milagre: registros periciais da lepra na Marinha do Brasil. Arq Bras Med Naval. 2017; 78(1): 61-68.

6. Franco IL, Magalhães JZ, Ricci EL, Abreu GR, Munhoz C, Fukushima AR. Revisão bibliográfica de protocolos e tratamento farmacológico de hanseníase utilizando o medicamento dapsona. Revinter. 2018; 11(2): 57-72.

7. Ferreira IN. Um breve histórico da hanseníase. Humanidades \& Tecnologia - FINOM 2019. 2019; 1(16): 436-454.

8. Figueiredo PV, Heinen RC. Poliquimioterapia no tratamento da hanseníase. Rev Saúde Física \& mental. 2017; 5(2): 56-69.

9. Neiva RJ. Perspectivas históricas do diagnóstico e tratamento da hanseníase. Saude Transf Soc. 2016; 7(1): 88-97.

10. Mantellini GG, Goncalves A, Padovani CR. Políticas públicas referentes às incapacidades físicas em hanseníase na virada do século: uma década de (des)controle? Physis. 2019, Rio de Janeiro, 29(1): e290105.

11. Brasil. Ministério da Saúde. Secretaria de Vigilância em Saúde. Caracterização da situação epidemiológica da hanseníase e diferenças por sexo, Brasil, 2012-2016. Bol Epidemiol [periódico na internet]. 2018 [acessado em 30 setembro de 2019]; 49(1). [cerca de 10 p.] 
Disponível em: https://portalarquivos2.saude.gov.br/images/pdf/2018/janeiro/31/2018-004Hanseniase-publicacao.pdf

12. Instituto Brasileiro de Geografia e Estatística [Internet]. Rio de Janeiro: Estatísticas de Âmbito Social e Demográfico; c2019 [citado em 12 de Set 2019]. IBGE; [cerca de 1 tela]. Disponível em: https://www.ibge.gov.br/cidades-e-estados/pa/igarape-acu.html

13. Silva MI, Anjos QDS, Leal I. Reações Hansênicas Tipo I Diagnosticados no Período de 2010 a 2014 na Unidade Básica de Saúde da Família Albert Sabin no Município de Rolim de Moura-RO. Revesc. 2017; 1(2): 30-44.

14. Ribeiro GC, Lana FCF. Incapacidades físicas em hanseníase: caracterização, fatores relacionados e evolução. Cogitare Enfermagem. 2015; 20(3): 496-503.

15. Silva Sobrinho RA, Arcoverde MAM., Zilly A, Nihei OK, Souza DCS. Repercussões sociais: histórico da hanseníase. Varia Scientia-Ciências da Saúde. 2015; 1(2): 188-195.

16. Nogueira W, Mary LM, Otflia SJG, Tada MLRF. Perspectivas da eliminação da Hanseníase. Hansenol inte. 1995; 20(1): 19-28.

17. Souza ÁPS, Silva DLGD, Silava EGD, Batista WA, Khouri AG, Oliveira RDFR, et al. Novas Perspectivas do Diagnóstico e Tratamento da Hanseníase. Referências em Saúde da Faculdade Estácio de Sá de Goiás-RRS-FESGO. 2019; 2(2): 78-81.

18. Costa MS, Júnior PCBS, Moura JPG, Pantoja PVN, Silva MP da. Políticas para hanseníase: a evolução da gestão em saúde. Rev enf. 2015; 1(2): 104-108.

19. Brasil. Ministério da Saúde. Secretaria de Vigilância em Saúde. Departamento de Vigilância das Doenças Transmissíveis. Guia prático sobre a hanseníase. Brasília, 2017. 